\title{
Water bears in the Anthropocene: a comparison of urban and woodland tardigrade (Phylum Tardigrada) communities in Southwestern Louisiana, USA
}

\author{
Harry A. MEYER, ${ }^{*}$ Juliana G. HINTON, Cari A. SAMLETZKA \\ Department of Biology and Health Sciences, McNeese State University, 4205 Ryan St., Lake Charles, 70609 LA, USA \\ *Corresponding author: hmeyer@mcneese.edu
}

\begin{abstract}
Humans have had such a profound effect on global ecosystems, including biodiversity, that Anthropocene is being increasingly used as a chronological term to mark the period of greatest human impact. No areas show the effect of human impact on the environment more than cities, which often have novel combinations of species in unique communities. Tardigrades (Phylum Tardigrada) have often been collected in cities, but studies dedicated to urban tardigrade biodiversity are few, and those comparing urban diversity with nearby rural or natural sites even fewer. In this paper we compare the diversity and abundance of tardigrade species in Lake Charles with a nearby forested nonurban site, Sam Houston Jones State Park (SHJSP). Although tardigrade density did not differ significantly between Lake Charles and SHJSP, species richness and diversity were greater in SHJSP (17 species, $\left.H_{1}=3.01\right)$ than in Lake Charles $\left(8\right.$ species, $\left.H_{1}=1.30\right)$. All but one species found in Lake Charles also occurred in SHJSP. The number of species found in Lake Charles lies within the range (5-10) found in previous urban surveys. All tardigrade studies comparing urban with nearby nonurban habitats have found lower species richness in cities.
\end{abstract}

Key words: Tardigrada, urban ecology, tardigrade ecology, biogeography.

\section{INTRODUCTION}

The distribution and abundance of species in the modern world is not solely the result of natural, non-anthropogenic factors. Anthropogenic biomes (urban, village, cropland, rangeland and semi-natural forest) cover more than $75 \%$ of Earth's ice-free land (Ellis and Ramankutty, 2008). Indeed, human-caused changes to the Earth's climate, land, oceans and biosphere are now so pervasive that the establishment of a new geological epoch, the Anthropocene, defined by the actions of humans, is being seriously considered (Zalasiewicz et al., 2011).

Humans generate spatial heterogeneity as they transform land, extract resources, introduce exotic species, and modify natural agents of disturbance, and nowhere is this more evident than in cities and other urbanising areas (Alberti, 2008). Human activities directly affect land cover, which controls primary productivity and biotic diversity (Sukopp, 1990). Urbanising areas often have novel combinations of species in unique communities, with diversity peaking at intermediate levels of urbanisation (Alberti et al., 2003). Disparate biotas in widely-separated areas can become more homogenised with increasing urbanisation (Olden and Rooney, 2006).

Terrestrial tardigrades (Phylum Tardigrada) are microscopic panarthropods frequently found in moss, lichens, liverworts, leaf litter and soil. Although tardigrades have often been collected from urban settings (Curtin, 1948), studies designed to investigate urban tardigrade diversity are few, and those comparing urban with nearby rural or natural habitats even fewer. Grothman (2011) collected twelve species of tardigrades from the grasslands and woods of a large urban park in Calgary, Canada, but did not collect in the city proper. Moly de Peluffo et al. (2006) and Peluffo et al. (2007) examined tardigrade distribution and diversity in two Argentine cities, but did not compare these to surrounding non-urban areas. Mitchell et al. (2009) investigated tardigrade diversity on an urban university campus in Philadelphia, USA. Steiner (1994a, 1994b, 1994c) collected extensively in Zürich, Switzerland, and nearby rural areas but his reported tardigrade diversity data did not distinguish between the two habitats. In a series of published abstracts, Utsugi $(1985,1986,1987,1988,1990,1992)$ summarised the results of a comprehensive tardigrade survey of 25 Japanese cities and surrounding areas. However, Utsugi did not publish his full results, and the abstracts do not directly contrast urban and non-urban tardigrade diversity.

Three studies have explicitly compared urban and rural or peri-urban tardigrade community composition: Séméria (1981, 1982) in Nice, France; Meininger et al. (1985) in Cincinnati, USA, and Johansson et al. (2011) in Fresno, USA. In this paper we compare the diversity of tardigrade communities in the city of Lake Charles with nearby woodland in Sam Houston Jones State Park (SHJSP). We do not address environmental or other factors that might result in differences between these communities.

\section{METHODS}

\section{Study sites}

Lake Charles and SHJSP are located in Calcasieu 
Parish, Louisiana, USA. The area is part of the West Gulf Coastal Plain; elevation ranges from sea level to $29 \mathrm{~m}$. Summers in Calcasieu Parish are hot and humid; winters are warm but are occasionally interrupted by freezing temperatures (Hardner, 1960; Roy and Midkiff, 1988) with a normal annual range of 5.1 to $31.6^{\circ} \mathrm{C}$ (National Weather Service Lake Charles Office). Annual precipitation averages $135.1 \mathrm{~cm}$ (Roy and Midkiff, 1988). The parish is frequently impacted by hurricanes. Approximately $46 \%$ of Calcasieu Parish land is devoted to agriculture or rangeland (rice, soybeans and cattle), $23 \%$ is woodland, $11 \%$ is marsh and $4 \%$ is swamp (Roy and Midkiff, 1988). The remaining $16 \%$ is urban. Lake Charles (population 72,000 in 2010 Census) is a deep-water port connected to the Gulf of Mexico (Jones et al., 1954). Large petroleum-related industries are located near Lake Charles.

Sam Houston Jones State Park consists primarily of bottomland forest along the Calcasieu river, while the area where Lake Charles now stands was originally bottomland forest, swampland and coastal prairie (Neyland et al., 2000). Most of Louisiana's original forests were logged in the Nineteenth and Twentieth Centuries, including the area now incorporated in SHJSP. Vegetation structure in SHJSP can also be significantly impacted by hurricanes, most recently by Hurricane Rita in 2005 . Therefore the woodland in SHJSP constitutes secondary forest as defined by Chokkalingam and de Jong (2001), i.e., a forest regenerated largely through natural processes after significant human and/or natural disturbance of the original forest vegetation. In the typology of Chokkalingam and de Jong (2001) the forest in SHJSP is a combination of post-catastrophic and post-extraction secondary forest.

\section{Sampling and analysis}

Sampling was conducted in spring, 2011. At SHJSP 52 samples (27 moss, 15 lichen, 2 mixed cryptogams and 8 leaf litter) were collected from trees and the forest floor. Sampling was distributed among the Longleaf Pine, Blue, river Walk and Yellow Trail regions of the park (13 samples per region, all substrate types collected in each region). In Lake Charles 40 samples were collected (24 lichen, 8 moss, 1 mixed cryptogam, 1 tree fern and 6 leaf litter), with eight samples from each of five urban landscape types: single family residential (all substrates), undeveloped lot (all substrates), light commercial property (no leaf litter), dense commercial property (all substrates) and industrial zone (no moss). These landscape types were chosen to represent a wide range of typical urban habitats. Samples were stored in paper envelopes or bags. The preponderance of moss samples in the forest and lichens in the city reflects their relative availability in the sites.

In the laboratory samples were air dried for $24 \mathrm{~h}$ and weighed to the nearest $0.01 \mathrm{~g}$ using an Acculab EC211 electronic balance, placed in tap water and soaked overnight to rehydrate tardigrades. After soaking they were examined with a dissecting microscope (Nikon SMZ-U Zoom 1:10). Tardigrade specimens and eggs were extracted with an Irwin loop and mounted on slides in polyvinyl lactophenol and examined using phase microscopy (Nikon Eclipse 50i; Nikon, Tokyo, Japan). Tardigrades were identified using keys and descriptions in Nelson and McInnes (2002), Pilato and Binda (2010) and Ramazzotti and Maucci (1983), and by reference to the primary literature. Taxonomic nomenclature is based on Guidetti and Bertolani (2005), Degma and Guidetti (2007) and Degma et al. (2012).

The statistical program EstimateS Version 8.2.0 was used to estimate species richness (Colwell, 2006), using the seven estimators included in EstimateS (Chao 1, Chao 2, ACE, ICE, Jacknife 1, Jacknife 2, and Bootstrap). No single estimator is accurate for all tardigrade habitats (Bartels and Nelson, 2007). To eliminate biases in estimated species richness caused by the patchy distribution characteristic of tardigrades (Meyer, 2006), we used 100 randomizations and patchiness set at zero. Because of the disparate types of samples (leaf litter, moss on trunks, lichens wrapped around twigs, etc.) determination of tardigrade density per unit area was not feasible; density per gram substrate was used as a crude approximation. Density and diversity were compared using formulas found in Cox (2001).

\section{RESULTS}

A total of 1470 tardigrade specimens from seventeen species and eight genera were found in moss, lichen and leaf litter samples from SHJSP and Lake Charles (Tab. 1); 1384 were identifiable. At SHJSP $63 \%$ of the samples contained tardigrades; in Lake Charles $68 \%$ of the samples were positive. Tardigrade density in samples positive for tardigrades ( 8.8 specimens $\mathrm{g}^{-1}$ at SHJSP and 14.0 specimens $\mathrm{g}^{-1}$ in Lake Charles) did not differ significantly (ttest, $\mathrm{P}=0.54)$. However, species richness at SHJSP (seventeen species) was more than double that in Lake Charles (eight); diversity was significantly greater at SHJSP than in Lake Charles (Shannon-Weiner Index: SHJSP, $H^{\prime}=3.01$; Lake Charles, $H^{\prime}=1.30$; t-test, $\mathrm{P}<0.05$ ). Mean estimates of tardigrade species richness predicted by the seven estimators in EstimateS ranged from 18 to 26 at SHJSP and from 8 to 11 in Lake Charles. The maximum number of species found in a single sample was four at both sites.

The tardigrade fauna of Lake Charles was dominated by two species (nearly $80 \%$ of all specimens), Minibiotus acadianus Meyer and Domingue, 2011 (primarily in cryptogams) and Paramacrobiotus richtersi (Murray, 1911) (in leaf litter). Paramacrobiotus richtersi was only found in undeveloped lots, which was the urban landscape with the most well-developed leaf litter. Minibiotus acadianus 
was collected in all landscapes except undeveloped lots. The number of species found in the different urban landscape types ranged from two in undeveloped lots to five in the industrial zone (species richness in other landscapes: residential 4, light commercial 3, heavy commercial 3). At SHJSP the most abundant species, Macrobiotus cf. echinogenitus, constituted about a third of the tardigrades. It was found in all regions of the park, as was Milnesium sp.

Tab. 1 shows from which substrates tardigrade species were collected. Three species (Milnesium $\mathrm{cf}$. reticulatum, Macrobiotus cf. echinogenitus and M. acadianus) were present in all substrates.

The absence of eggs precluded specific identification of Macrobiotus cf. echinogenitus, Macrobiotus cf. harmsworthi, and Minibiotus cf. intermedius. Macrobiotus $\mathrm{cf}$. hufelandi and Milnesium $\mathrm{cf}$. reticulatum are undescribed species which will be described elsewhere.

\section{DISCUSSION}

Three species collected at SHJSP in this study Echiniscus perarmatus Murray, 1907, Hypsibius dujardini (Doyère, 1840) and Paramacrobiotus tonollii (Ramazzotti, 1956) - are new to the fauna of Louisiana. Earlier papers (Meyer, 2001; Hinton et al., 2010) recorded eleven species from SHJSP. Three of these species - Diphascon (Diphascon) pingue (Marcus, 1936), Astatumen trinacriae (Arcidiacono, 1962) and Itaquascon cf. umbellinae were not collected in this study. Only one species, Macrobiotus occidentalis Murray, 1910, has previously

Tab. 1. Tardigrade diversity in cryptogams and leaf litter from Sam Houston Jones State Park and Lake Charles, LA: number of samples positive for a species, number of specimens, and substrates.

\begin{tabular}{|c|c|c|}
\hline Species & $\begin{array}{l}\text { Positive s } \\
\text { (number of specin } \\
\text { SHJSP }\end{array}$ & Lake Charles \\
\hline Echiniscus cavagnaroi Schuster and Grigarick, 1966 & $1(1 ; 1 \mathrm{c})$ & 0 \\
\hline Echiniscus perarmatus Murray, 1907 & $1(39 ; \mathrm{m})$ & 0 \\
\hline Echiniscus virginicus Riggin, 1962 & $3(10 ; \mathrm{m})$ & 0 \\
\hline Pseudechiniscus brevimontanus Kendall-Fite and Nelson, 1996 & $1(1 ; \mathrm{m})$ & 0 \\
\hline Milnesium sp. ([3-3]-[3-3] claw configuration) & $13(80 ; 1 \mathrm{c}, \mathrm{m})$ & $3(27 ; 1 c)$ \\
\hline Milnesium cf. reticulatum & $3(20 ; 1 \mathrm{c}, 11)$ & $15(70 ; 1 \mathrm{c}, 11, \mathrm{~m})$ \\
\hline Hypsibius dujardini (Doyère, 1840) & 0 & $2(4 ; 1 \mathrm{c}, 11)$ \\
\hline Isohypsibius $\mathrm{sp}$. & $1(2 ; 11)$ & 0 \\
\hline Macrobiotus cf. echinogenitus & $12(213 ; 1 \mathrm{c}, 11, \mathrm{~m})$ & $3(10 ; 1 c)$ \\
\hline Macrobiotus cf. harmsworthi & $3(11 ; 11)$ & $3(20 ; 1 \mathrm{c}, 11)$ \\
\hline Macrobiotus cf. hufelandi & $4(57 ; \mathrm{m})$ & 0 \\
\hline Macrobiotus occidentalis Murray, 1910 & $1(1 ; 1 \mathrm{c})$ & 0 \\
\hline Minibiotus acadianus Meyer and Domingue, 2011 & $4(17 ; \mathrm{lc}, \mathrm{m})$ & $17(334 ; 1 \mathrm{c}, 11, \mathrm{~m})$ \\
\hline Minibiotus cf. intermedius & $7(21 ; 1 \mathrm{c}, \mathrm{m})$ & 0 \\
\hline Paramacrobiotus areolatus (Murray, 1907) & $3(21 ; \mathrm{lc}, \mathrm{m})$ & $2(9 ; \mathrm{lc}, \mathrm{m})$ \\
\hline Paramacrobiotus richtersi (Murray, 1911) & $6(30 ; 11, \mathrm{~m})$ & $3(342 ; 1 \mathrm{c}, 11, \mathrm{~m})$ \\
\hline Paramacrobiotus tonollii (Ramazzotti, 1956) & $6(44 ; \mathrm{lc}, \mathrm{m})$ & 0 \\
\hline
\end{tabular}

lc, lichen; ll, leaf litter; $m$, moss.

Tab. 2. Urban and non-urban terrestrial tardigrade species richness in and near seven cities.

\begin{tabular}{|c|c|c|c|}
\hline City (2012 population) & $\begin{array}{l}\text { Numbe } \\
\text { Urban }\end{array}$ & Non-urban & Reference \\
\hline Cincinnati, USA $(297,000)$ & 5 & 8 & Meininger et al. (1985) \\
\hline Fresno, USA $(510,000)$ & 10 & 19 & Johansson et al. (2011) \\
\hline General Pico, Argentina $(54,000)$ & 5 & Unknown & Moly de Peluffo et al. (2006) \\
\hline Lake Charles, USA $(72,000)$ & 8 & 16 & Present study \\
\hline Nice, France $(345,000)$ & 4 & 16 & Séméria $(1981,1982)$ \\
\hline Philadelphia, USA (1.5 million) & 8 & Unknown & Mitchell et al. (2009) \\
\hline Santa Rosa, Argentina $(97,000)$ & 5 & Unknown & Peluffo et al. (2007) \\
\hline Tokyo, Japan (13 million) & 10 & Unknown & Utsugi (1985) \\
\hline
\end{tabular}


been reported from Lake Charles (Meyer, 2001); it was not found there in this study. Minibiotus acadianus has hitherto only been recorded from its type locality in Acadia Parish, Louisiana (Meyer and Domingue, 2011).

Earlier studies have assessed tardigrade diversity in seven urban areas (Tab. 2) with human populations ranging from 54,000 (General Pico) to over 13 million (Tokyo). The number of tardigrade species found in these cities ranges from four to ten (Tab. 2); Lake Charles falls within this range. In four studies comparing urban to non-urban tardigrade diversity (Tab. 2), urban species richness is consistently lower than non-urban (from 25 to $63 \%$ ). The proportion of samples containing tardigrades ranges in these studies from 38\% (Fresno) to 98\% (General Pico).

Johansson et al. (2011) noted that in Fresno very few species were common to both urban and rural sites. On the other hand, in Cincinnati, Lake Charles and Nice most species found in urban sampling were also present in urban areas. The tardigrade taxa most widely reported from cities are Milnesium sp. and Ramazzottius oberhaeuseri (Doyère, 1840); the latter was not found in Lake Charles. Several authors (Séméria, 1981, 1982; Meininger et al., 1985; Steiner, 1994b) have suggested that certain tardigrades species [e.g., Milnesium tardigradum Doyère, 1840, Macrobiotus hufelandi C.A.S. Schultze, 1936, Ramazzottius oberhaeuseri and Diphascon (Diphascon) scoticum Murray, 1905] have high resistance to urban environmental conditions and may therefore be characteristic of cities worldwide. However, different urban tardigrade studies tend to find a different suite of species in their cities (Johansson et al., 2011). Since some species widely reported in cities belong to species complexes, identifications in older literature need to be confirmed, and claims that individual species are characteristic of urban faunas worldwide must be treated with caution. It is worth noting that tardigrades of the class Heterotardigrada have been collected in only three of eight urban areas surveyed (General Pico, Santa Rosa and Tokyo), but were abundant in all non-urban surveys.

While this study did not attempt to determine the cause of differences in tardigrade diversity between urban and non-urban habitats, other papers have demonstrated the effects of human actions on tardigrade distribution and abundance. Tardigrade densities in lichens were lower in trees treated with DDT (Barrett and Kimmel, 1972) or downwind of a coal-burning plant (Hohl et al., 2001), while proximity to road-generated dust altered tardigrade species composition (Meininger and Spatt, 1988). In urban environments, lower tardigrade species richness in urban areas has been related to vehicular traffic and air quality (Meininger et al., 1985; Steiner 1994b; Moly de Peluffo et al., 2006, Peluffo et al., 2007). However, Johansson et al. (2011) found no relationship between lower urban tardigrade diversity and lower $\mathrm{pH}$.

\section{CONCLUSIONS}

Tardigrade species richness and diversity in Lake Charles were substantially less than in a nearby forest, although tardigrade density did not differ. Similar patterns have been found in other studies comparing urban and nonurban areas. The degree to which tardigrade diversity may vary within a city (i.e., between urban landscapes ranging from parks to densely inhabited zones) and whether urbanisation is homogenising global tardigrade fauna remain unanswered questions worthy of further research.

\section{ACKNOWLEDGMENTS}

We wish to thank the McNeese State University Alumni Association for supporting C.A. Samletzka's undergraduate research project.

\section{REFERENCES}

Alberti M, 2008. Advances in urban ecology: integrating humans and ecological processes in urban environments. Springer Science+Business Media.

Alberti M, Marzluff J, Shulenberger E, Bradley G, Ryan C, Zumbrunnen C, 2003. Integrating humans into ecology: opportunities and challenges for studying urban ecosystems. BioScience 53:1169-1179.

Barrett GW, Kimmel RG, 1972. Effects of DDT on the density and diversity of tardigrades. Proc. Iowa Acad. Sci. 78:41-42.

Bartels PJ, Nelson DR, 2007. An evaluation of species richness estimators for tardigrades of the Great Smoky Mountains National Park, Tennessee and North Carolina, USA. J. Limnol. 66(Suppl. 1):104-110.

Chokkalingam U, de Jong W, 2001. Secondary forest: a working definition and typology. Int. Forest Rev. 3:19-26.

Colwell RK, 2006. EstimateS: statistical estimation of species richness and shared species from samples. Version 8. Available from: http://viceroy.eeb.uconn.edu/estimates

Cox GW, 2001. Laboratory manual of general ecology. Wm. C. Brown Publ., Dubuque, IA, USA.

Curtin CB, 1948. The tardigrade fauna of the District of Columbia. J. Wash. Acad. Sci. 38:251-254.

Degma P, Bertolani R, Guidetti R, 2012. Actual checklist of Tardigrada species (2009-2012, Ver. 21:30-06-2012). Available from: http://www.tardigrada.modena.unimo.it/miscellanea

Degma P, Guidetti R, 2007. Notes to the current checklist of Tardigrada. Zootaxa 1579:41-53.

Ellis EC, Ramankutty N, 2008. Putting people in the map: anthropogenic biomes of the world. Front. Ecol. Environ. 6:439-447.

Grothman GT, 2011. Tardigrades of Fish Creek Provincial Park, Alberta, Canada: a preliminary survey. Can. Field-Nat. 125:22-26.

Guidetti R, Bertolani R, 2005. Tardigrade taxonomy: an updated checklist of the taxa and a list of characters for their identification. Zootaxa 845:1-46.

Hardner AH, 1960. The geology and ground-water resources of Calcasieu Parish, Louisiana. United States Printing Office, Washington, DC, USA.

Hinton JG, Meyer HA, Sweeney AW, 2010. Seasonal and spatial 
variation in diversity and abundance of tardigrades in leaf litter from Louisiana and Florida. Southwest. Nat. 55:539-543.

Hohl AM, Miller WR, Nelson DR, 2001. The distribution of tardigrades upwind and downwind of a Missouri coal-burning power plant. Zool. Anz. 240:395-401.

Johansson C, Calloway S, Miller WR, Linder ET, 2011. Are urban and rural tardigrade (Tardigrada) communities distinct and determined by $\mathrm{pH}$ : a case study from Fresno County, California. Pan-Pac. Entomol. 87:86-97.

Jones PH, Turcan AN, Skibitzke HE, 1954. Geology and ground-water resources of southwestern Louisiana. Department of Conservation, Louisiana Geological Survey.

Meininger CA, Spatt PD, 1988. Variations in tardigrade assemblages in dust-impacted Arctic mosses. Arctic Alpine Res. 20:23-30.

Meininger CA, Uetz GW, Snider JA, 1985. Variation in epiphytic microcommunities (tardigrade-lichen-bryophyte assemblages) of the Cincinnati, Ohio area. Urban Ecol. 9:45-61.

Meyer HA, 2001. Tardigrades of Louisiana and Arkansas, United States of America. Zool. Anz. 540:471-474.

Meyer HA, 2006. Small-scale spatial distribution heterogeneity in terrestrial tardigrade populations. Hydrobiologia 558:133139.

Meyer HA, Domingue MN, 2011. Minibiotus acadianus (Eutardigrada: Macrobiotidae), a new species of Tardigrada from southern Louisiana, USA. West. N. Am. Nat. 71:38-43.

Mitchell CR, Miller WR, Davis B, 2009. Tardigrades of North America: influence of substrate on habitat selection. J. Penn. Acad. Sci. 83:10-16.

Moly de Peluffo MC, Peluffo JR, Rocha AM, Doma IL, 2006. Tardigrade distribution in a medium-sized city of central Argentina. Hydrobiologia 558:141-150.

Nelson DR, McInnes SJ, 2002. Tardigrada, p. 177-215. In: S.D. Rundle, A. Robertson and J.M. Schmid-Araya (eds.), Freshwater meiofauna: biology and ecology. Backhuys Publishers.

Neyland R, Hoffman BJ, Mayfield M, Urbatsch LL, 2000. A vascular flora survey of Calcasieu Parish, Louisiana. Sida 19:361-386.

Olden JD, Rooney TP, 2006. On defining and quantifying biotic homogenization. Global Ecol. Biogeogr. 15:113-120.

Peluffo JR, Rocha AM, Moly de Peluffo MC, 2007. Species diversity and morphometrics of tardigrades from a mediumsize city in the Neotropical Region: Santa Rosa (La Pampa, Argentina). Anim. Biodivers. Conserv. 30:43-51.
Pilato G, Binda MG, 2010. Definition of families, subfamilies, genera and subgenera of the Eutardigrada, and keys to their identification. Zootaxa 2404:1-54.

Ramazzotti G, Maucci W, 1983. [Il Phylum Tardigrada. Terza edizione riveduta e corretta]. [Article in Italian]. Mem. Ist. ital. Idrobiol. 41:1-1011.

Roy AJ, Midkiff CT, 1988. Soil survey of Calcasieu Parish, Louisiana. Soil Conservation Service, United States Department of Agriculture.

Séméria Y, 1981. [Recherches sur la faune urbaine et sub-urbaine des tardigrades muscicoles et lichenicoles. 1. NiceVille]. [Article in French]. Bull. Mens. Soc. Linn. Lyon 50:231-237.

Séméria Y, 1982. [Recherches sur la faune urbaine et sub-urbaine des tardigrades muscicoles et lichenicoles. 2. L'espace sub-urbain: les hauteurs orientales de Nice-Ville]. [Article in French]. Bull. Mens. Soc. Linn. Lyon 51:315-328.

Steiner WA, 1994a. The influence of air pollution on mossdwelling animals: 1 . Methodology and composition of flora and fauna. Rev. Suisse Zool. 101:533-556.

Steiner WA, 1994b. The influence of air pollution on mossdwelling animals: 2. Aquatic fauna with emphasis on $\mathrm{Ne}$ matoda and Tardigrada. Rev. Suisse Zool. 101:699-724.

Steiner WA, 1994c. The influence of air pollution on mossdwelling animals: 4. Seasonal and long-term fluctuations of rotifer, nematode and tardigrade populations. Rev. Suisse Zool. 101:1017-1031.

Sukopp H, 1990. Urban ecology and its application to Europe, p. 1-22. In: H. Sukopp and S. Hejny (eds.), Urban ecology: plants and plant communities in urban environments. SPB Publishing.

Utsugi K, 1985. Urban tardigrades in Tokyo. Zool. Sci. 2:1006.

Utsugi K, 1986. Urban tardigrades in Kyushu. Zool. Sci. 3:1110

Utsugi K, 1987. Urban Tardigrades in Hokuriku Area. Zool. Sci. 4:1111.

Utsugi K, 1988. Tardigrades in Hokkaido Area. Zool. Sci. 5:1335

Utsugi K, 1990. Heterotardigrades in Japan. Zool. Sci. 7:1183.

Utsugi K, 1992. Urban tardigrades in the Tohoku Area. Zool. Sci. 9:1297.

Zalasiewicz J, Williams M, Haywood A, Ellis M, 2011. The Anthropocene: a new epoch of geological time? Phil. Trans. Roy. Soc. A 369:835-841. 